\title{
Article \\ An Application of Imipenem Discs or P. aeruginosa ATCC 27853 Reference Strain Increases Sensitivity of Carbapenem Inactivation Method for Non-Fermenting Gram-Negative Bacteria
}

\author{
Tomasz Bogiel *(D), Mateusz Rzepka (D) and Eugenia Gospodarek-Komkowska \\ Microbiology Department, Ludwik Rydygier Collegium Medicum in Bydgoszcz, Nicolaus Copernicus University \\ in Torun, 9 Maria Skłodowska-Curie St, 85-094 Bydgoszcz, Poland; mateusz.rzepka@cm.umk.pl (M.R.); \\ gospodareke@cm.umk.pl (E.G.-K.) \\ * Correspondence: t.bogiel@cm.umk.pl; Tel.: +48-52-585-44-80
}

check for

updates

Citation: Bogiel, T.; Rzepka, M.; Gospodarek-Komkowska, E. An Application of Imipenem Discs or P. aeruginosa ATCC 27853 Reference

Strain Increases Sensitivity of Carbapenem Inactivation Method for Non-Fermenting Gram-Negative Bacteria. Antibiotics 2021, 10, 875. https://doi.org/10.3390/ antibiotics10070875

Academic Editor: Todd Robert Steck

Received: 12 June 2021

Accepted: 16 July 2021

Published: 19 July 2021

Publisher's Note: MDPI stays neutral with regard to jurisdictional claims in published maps and institutional affiliations.

Copyright: (c) 2021 by the authors. Licensee MDPI, Basel, Switzerland. This article is an open access article distributed under the terms and conditions of the Creative Commons Attribution (CC BY) license (https:// creativecommons.org/licenses/by/ $4.0 /)$.

\begin{abstract}
Non-fermenting Gram-negative rods are one of the most commonly isolated bacteria from human infections. These microorganisms are typically opportunistic pathogens that pose a serious threat to public health due to possibility of transmission in the human population. Resistance to beta-lactams, due to carbapenemases synthesis, is one of the most important antimicrobial resistance mechanisms amongst them. The aim of this study was to evaluate the usefulness of the Carbapenem Inactivation Method (CIM), and its modifications, for the detection of carbapenemase activity amongst non-fermenting Gram-negative rods. This research involved 81 strains of Gramnegative rods. Of the tested strains, 55 (67.9\%) synthesized carbapenemases. For non-fermenting rods, $100 \%$ sensitivity and specificity was obtained in the version of the CIM test using imipenem discs and E. coli ATCC 25922 strain. The CIM test allows for differentiation of carbapenems resistance mechanisms resulting from carbapenemase synthesis from other resistance types. It is a reliable diagnostic method for the detection of carbapenemase activity amongst non-fermenting Gram-negative rods. Application of imipenem discs and P. aeruginosa ATCC 27853 reference strain increases CIM results sensitivity, while imipenem discs and E. coli ATCC 25922 strain use maintains full precision of the test for non-fermenting rods.
\end{abstract}

Keywords: Acinetobacter baumannii; carbapenemases; carbapenemase detection; carbapenems; CIM; Gram-negative rods; imipenem; non-fermenting rods; Pseudomonas aeruginosa

\section{Introduction}

Non-fermenting Gram-negative rods are one of the most commonly isolated bacteria from human infections, especially in immunocompromised individuals. Their natural resistance to antimicrobials and relatively low nutritional requirements classify them as some of the most dangerous hospital pathogens. In addition, these bacteria have a possibility to exchange genetic material, including those encoding acquired antimicrobial resistance mechanisms [1,2]. One of the mentioned mechanisms may be resistance to carbapenems, which are often the last-chance drugs in the treatment of infections caused by Gram-negative rods, both for members of the Enterobacterales order and non-fermenters. Resistance to carbapenems is most often of enzymatic nature (synthesis of carbapenemasesenzymes hydrolyzing a number of beta-lactam group drugs). Due to the possibility of horizontal and vertical transmission of carbapenemases coding genes, it is necessary to effectively detect bacterial strains with this drug-resistance phenotype [3-5]. It is of great epidemiological importance in terms of both limiting the frequency of infection as well as these strains spreading in the environment. However, the available diagnostic methods for detecting carbapenemase activity amongst Gram-negative rods differ significantly in their sensitivity and specificity. 
Many methods are currently used to detect carbapenemase amongst Gram-negative rods $[4,6]$. Chromogenic media may be used to culture and relatively quickly identify strains of carbapenem-resistant bacteria directly from a clinical specimen. It is a screening method based on the ability of bacteria to grow on a selective medium with the addition of an antibiotic [7]. Carba NP and CarbAcineto biochemical tests are other relatively fast methods [8,9]. Their principle is based on the hydrolysis of imipenem by a lysate of carbapenemase-producing bacteria. A positive result decreases $\mathrm{pH}$ in the reaction medium, and changes the indicator color (phenol red) [10,11]. The European Committee on Antimicrobial Susceptibility Testing (EUCAST) also recommends the use of specific tests based on the disc diffusion method: ethylenediaminetetraacetic acid (EDTA) test for metallo-beta-lactamases, boronic acid test for KPC (Klebsiella pneumoniae Carbapenemases) and temocillin test for OXA-48-like enzymes. However, the last mentioned test shows low specificity for OXA-48 type carbapenemases [6]. It also fails to detect oxacillinases, which are often produced by non-fermenting rods. For this reason, synthesis of these enzymes should be confirmed by other available methods [6]. This involves methods such as mass spectrometry and the Carbapenem Inactivation Method (CIM), developed in 2015 and applied to detect carbapenemases exclusively [6,12].

The aim of this study was to: (1) evaluate CIM test usefulness for the detection of carbapenemases activity amongst non-fermenting Gram-negative rods using primary test version-meropenem discs and Escherichia coli ATCC 25922 strain; (2) evaluate usefulness of CIM test modifications-using imipenem discs and/or Pseudomonas aeruginosa ATCC 27853 strain; (3) compare the results of the applied CIM versions.

\section{Materials and Methods}

\subsection{Bacterial Isolates}

In this study, 81 strains of Gram-negative rods were used. This selection included isolates obtained from the Microbiology Department of the Ludwik Rydygier Collegium Medicum in Bydgoszcz Nicolaus Copernicus University in Torun (Poland) collection and reference strain (Table S1). Based on the results obtained by the MALDI-TOF MS method (Matrix-Assisted Laser Desorption/Ionization Time-of-Flight Mass Spectrometry) (MALDIBiotyper, Bruker Daltonik, Germany), the strains were identified and subsequently divided into two species: Acinetobacter baumannii $(n=44,54.3 \%)$ and P. aeruginosa $(n=37,45.7 \%)$ (Tables 1 and 2 ). They were isolated from various patients, different clinical specimens, from cases of infections or colonization (Table S1). The susceptibility of the tested strains was previously determined during the diagnostic procedures: $76(93.8 \%)$ strains were resistant to at least one of the carbapenems (imipenem or meropenem), while 5 (6.2\%) strains were sensitive or intermediate to the mentioned beta-lactams. The interpretation of the susceptibility determination of the strains was made from the document "European Committee on Antimicrobial Susceptibility Testing, Breakpoint tables for interpretation of MICs and zone diameters, Version 7.1, valid from 10 March 2017" [13].

\subsection{Analysis of Carbapenemase-Positive Gram-Negative Rods}

The synthesis or absence of carbapenemases among the tested strains have been previously confirmed during standard diagnostic procedures and using additional molecular studies (Table S2). For this purpose, the following methods were used: Carba NP/CarbAcineto, disc-diffusion method (EDTA test), BD Phoenix NMIC-502 panels (Becton Dickinson) and genetic methods based on real-time polymerase chain reaction, IVD tests to detect carbapenemases encoding genes: VIM-, IMP-, KPC-, NDM-type, OXA-48 in CPE BD MAX Assay, Becton Dickinson or KPC-, VIM-type, NDM-1, OXA-48, OXA-181, CTX-M1, CTX-M9 of eazyplex SuperBug CRE test, Amplex Diagnostics. Of the 81 strains tested, 55 (67.9\%) were carbapenemase-positive. All of the tested strains have been characterized for the presence or absence of carbapenemase synthesis by at least two methods (phenotypic and/or molecular), performed independently and obtaining compatible results (Table S2). 
Table 1. CIM test results for the carbapenemases-positive strains $(n=55)$.

\begin{tabular}{|c|c|c|c|c|c|c|}
\hline \multirow[b]{2}{*}{ Strain } & \multirow[b]{2}{*}{ Carbapenemase } & \multirow[b]{2}{*}{$n$} & \multicolumn{2}{|c|}{ Meropenem } & \multicolumn{2}{|c|}{ Imipenem } \\
\hline & & & $\begin{array}{c}\text { E. coli ATCC } \\
25922\end{array}$ & $\begin{array}{l}\text { P. aeruginosa } \\
\text { ATCC } 27853\end{array}$ & $\begin{array}{c}\text { E. coli ATCC } \\
25922\end{array}$ & $\begin{array}{l}\text { P. aeruginosa } \\
\text { ATCC } 27853\end{array}$ \\
\hline $\begin{array}{l}\text { A. baumannii } \\
\text { DSM } 102930\end{array}$ & $\begin{array}{l}\text { Class B } \\
\text { (NDM-2) }\end{array}$ & 1 & + & + & + & + \\
\hline \multirow{6}{*}{ A. baumannii } & \multirow{3}{*}{$\begin{array}{l}\text { Class D } \\
\text { (OXA-23) }\end{array}$} & 12 & + & + & + & + \\
\hline & & 2 & - & + & + & + \\
\hline & & 1 & $-/+$ & + & + & + \\
\hline & \multirow{3}{*}{$\begin{array}{l}\text { Class D } \\
\text { (OXA-40) }\end{array}$} & 25 & + & + & + & + \\
\hline & & 1 & - & + & + & + \\
\hline & & 1 & $-/+$ & + & + & + \\
\hline \multirow{4}{*}{ P. aeruginosa } & \multirow{2}{*}{$\begin{array}{c}\text { Class B } \\
\text { (unidentified) }\end{array}$} & 4 & + & + & + & + \\
\hline & & 1 & - & + & + & + \\
\hline & \multirow{2}{*}{ Class B (VIM) } & 6 & + & + & + & + \\
\hline & & 1 & - & + & + & + \\
\hline
\end{tabular}

-- negative result, +-positive result, $-/+$ - equivocal result, ATCC—American Type Culture Collection, DSM-German Collection of Microorganisms and Cell Cultures, $n-$ number of isolates.

Table 2. CIM test results for the carbapenemases-negative strains $(n=26)$.

\begin{tabular}{cccccc}
\hline \multirow{2}{*}{ Strain } & & \multicolumn{2}{c}{ Meropenem } & \multicolumn{2}{c}{ Imipenem } \\
\cline { 2 - 6 } & $n$ & $\begin{array}{c}\text { E. coli ATCC } \\
\mathbf{2 5 9 2 2}\end{array}$ & $\begin{array}{c}\text { P. aeruginosa } \\
\text { ATCC 27853 }\end{array}$ & $\begin{array}{c}\text { E. coli ATCC } \\
\mathbf{2 5 9 2 2}\end{array}$ & $\begin{array}{c}\text { P. aeruginosa } \\
\text { ATCC 27853 }\end{array}$ \\
\hline $\begin{array}{c}\text { A. baumannii } \\
\text { DSM 30008 }\end{array}$ & 1 & - & + & - & + \\
\hline & 4 & - & - & - & - \\
\cline { 2 - 6 } & 18 & - & - & - & $-/+$ \\
\cline { 2 - 6 } & 1 & - & $-/+$ & - & + \\
\hline $\begin{array}{c}\text { P. aeruginosa } \\
\text { ATCC 27853 }\end{array}$ & 1 & - & + & - & $-/+$ \\
\hline
\end{tabular}

--negative result, +- positive result, $-/+$ - equivocal result, ATCC-American Type Culture Collection, DSMGerman Collection of Microorganisms and Cell Cultures, $n-$ number of isolates.

\subsection{Carbapenem Inactivation Method Procedure}

To perform CIM, the tested and reference strains were plated on Mueller-Hinton agar (MHA, bioMérieux) and incubated for $16 \mathrm{~h}$ at $37^{\circ} \mathrm{C}$.

The method was performed in the primary version using a meropenem disc $(10 \mu \mathrm{g})$ with an E. coli ATCC 25922 reference strain (A), and its three further modifications: (B) meropenem disc $(10 \mu \mathrm{g})$ and P. aeruginosa ATCC 27853 strain, (C) imipenem disc $(10 \mu \mathrm{g})$ with E. coli ATCC 25922 strain and (D) imipenem disc $(10 \mu \mathrm{g})$ and P. aeruginosa ATCC 27853 strain; antibiotic discs were purchased from Becton Dickinson.

To detect carbapenemase activity, suspensions of the tested strain were prepared simultaneously in two $1.5 \mathrm{~mL}$ test tubes (Eppendorf) by adding $800 \mu \mathrm{L}$ of sterile distilled water and two inoculation loops (approximately $10 \mu \mathrm{L}$ ) of bacteria. Then, two meropenem discs were added to the first tube and two imipenem discs to the second one. The suspensions, together with antibiotic discs, were incubated for $4 \mathrm{~h}$ at $35^{\circ} \mathrm{C}$ in a thermoblock (Thermomixer comfort; Eppendorf) with a mixing function (500 rpm). At the end of the incubation, two suspensions of the reference strains (E. coli ATCC 25922 and P. aeruginosa ATCC 27853) with a density of 0.5 of the McFarland scale were prepared in $0.9 \%$ sodium 
chloride (Polpharma). Subsequently, the suspensions were inoculated onto MHA using a disposable swab (Figure 1). Both mentioned strains are characterized by sensitivity to carbapenems, and were used in this study as indicator strains.

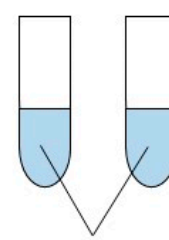

$800 \mu 1$ of sterile distilled $\mathrm{H}_{2} \mathrm{O}$

+ full loop $(10 \mu \mathrm{l})$ of bacteria
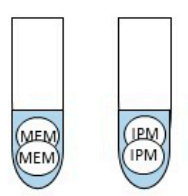

Addition of two:

- MEM disc $(10 \mu \mathrm{g})$

- IPM disc $(10 \mu \mathrm{g})$

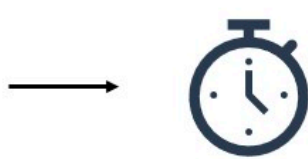

Incubation $\left(35^{\circ} \mathrm{C}, 4\right.$ hours $)$

Read out and interpretation of test results

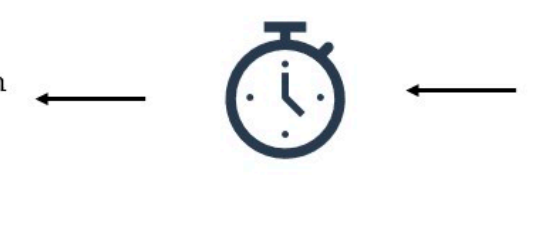

Incubation $\left(35^{\circ} \mathrm{C}, 16\right.$ hours $)$

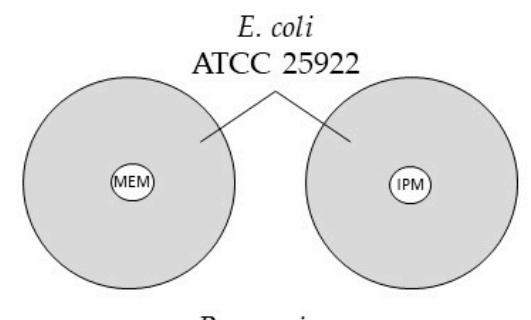

P. aeruginosa ATCC 27853

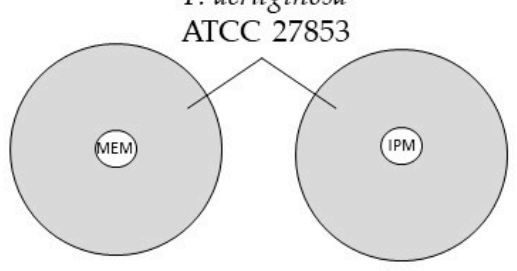

Transfer of antibiotics disc to MHA plate inoculated with reference strains

Figure 1. Project design of the primary version of CIM and its modification; ATCC-American Type Culture Collection, IPM-imipenem, MEM-meropenem, MHA-Mueller-Hinton agar.

After the incubation step, meropenem discs were removed from the suspensions of the tested strain and placed on an MHA plate inoculated with E. coli ATCC 25922 and $P$. aeruginosa ATCC 27853 strains, respectively. Imipenem discs were handled in the same manner. Incubation was carried out at $35^{\circ} \mathrm{C}$ for $16 \mathrm{~h}$, and the results were read out and interpreted afterwards.

\subsection{Interpretation Criteria for the Obtained CIM Results}

After the incubation step, the diameters of the growth inhibition zones of the reference strains around meropenem and imipenem discs were measured. Results interpretation criteria for the tested strains were based on the analysis of the results obtained for the control strains, as well as literature recommendations [14]. The results were classified as positive, ambiguous or negative when the diameters of the inhibition zone of $E$. coli ATCC 25922 strain were as follows: $15 \mathrm{~mm}$ or less, $16 \mathrm{~mm}-18 \mathrm{~mm}$ or $19 \mathrm{~mm}$ and more. The corresponding values for P. aeruginosa ATCC 27853 strain were: below or $12 \mathrm{~mm}$, $13 \mathrm{~mm}-15 \mathrm{~mm}$, and more than $15 \mathrm{~mm}$.

Figure 2 shows an example of CIM test results for positive and negative controls, and two strains tested on the MHA plate, with E. coli ATCC 25922 strain culture and meropenem discs.

Ambiguous results were classified as false negative when the tested strain was positive for carbapenemases or their genes. For the tested strains that did not synthesize carbapenemase or were negative for the carbapenemase gene, equivocal results were counted as false positive.

A narrow ring of growth around the discs resulting from the carryover of the tested bacteria in the water was ignored, according to the Clinical and Laboratory Standards Institute Guidelines and the recommendations of other researchers [14,15].

\subsection{Statistical Analysis}

The sensitivity and specificity of the tests, as well as $95 \%$ confidence intervals (CI), were calculated using PQStat for Windows, version 1.8.2 (PQStat Software, Poznan, Poland). Descriptive statistics were given as number and percentage for categorical variables. 


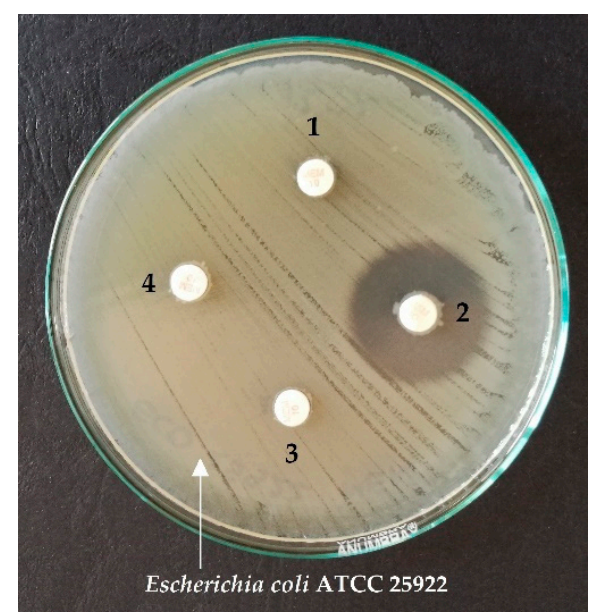

Figure 2. An example of CIM test results using meropenem discs and the reference strain E. coli ATCC 25922 for the chosen strains 1, 3, 4-positive results; 2-negative result.

\section{Results}

\subsection{CIM Test Results}

In variant A of the CIM test, using a meropenem disc and E. coli ATCC 25922 reference strain, positive results were obtained for $48(59.3 \%)$ strains and negative results for 31 (38.3\%) strains. Carbapenemases were not detected in three A. baumannii and two $P$. aeruginosa strains, giving false negative results. Ambiguous results were obtained for two A. baumannii strains (Table 1). For the bacteria previously found to be carbapenemase gene-positive, the CIM test was repeated to eliminate random laboratory mistakes and the results obtained initially and secondly were consistent.

In the modified version (B) of the CIM test, using a meropenem disc and P. aeruginosa ATCC 27853 reference strain, positive results were obtained for 57 (70.4\%). Negative results in the CIM test were found in $23(28.4 \%)$ carbapenemases-negative strains. Among the carbapenemase-negative strains, two false positive results were obtained (A. baumannii and $P$. aeruginosa), while for one $P$. aeruginosa strain the result was determined as equivocal (Table 2).

In variant $C$ of the $C I M$ test, with the replacement of the meropenem disc with an imipenem disc, positive results were obtained for $55(67.9 \%)$ and negative results for 26 $(32.1 \%)$ strains. No false results were found (Table 2).

Tables 1 and 2 also present the results of the CIM test in modification D, using the imipenem disc and P. aeruginosa ATCC 27853 reference strain. Positive results were obtained for $57(70.4 \%)$ strains, two of which were false positives (P. aeruginosa and A. baumannii). Negative results of the CIM test were obtained for 4 (4.9\%) strains. Of the carbapenemasenegative strains, $20(24.7 \%)$ showed ambiguous results.

\subsection{Evaluation of CIM Test Parameters in Its Different Variants}

The use of CIM test modifications resulted in an increase in the diagnostic sensitivity of the test. For non-fermenting rods, only the use of imipenem discs and E. coli ATCC 25922 strain (variant C) in the CIM test resulted in $100 \%$ values of both parameters (sensitivity and specificity) used to assess the usefulness of the diagnostic test (Table 3). 
Table 3. Diagnostic value of CIM test variants for non-fermenting rods $(n=81)$.

\begin{tabular}{|c|c|c|c|c|c|}
\hline \multicolumn{2}{|c|}{ Variant of CIM Test } & \multirow{2}{*}{$\begin{array}{c}\begin{array}{c}\text { Sensitivity } \\
{[\%]}\end{array} \\
\\
87.3\end{array}$} & \multirow{2}{*}{$\begin{array}{c}\text { 95\% CI } \\
75.5-94.7\end{array}$} & \multirow{2}{*}{$\begin{array}{c}\begin{array}{c}\text { Specificity } \\
{[\%]}\end{array} \\
100.0\end{array}$} & \multirow{2}{*}{$\begin{array}{c}95 \% \text { CI } \\
86.8-100.0\end{array}$} \\
\hline A & $\begin{array}{l}\text { Meropenem } \\
\quad+\text { E. coli } \\
\text { ATCC } 25922\end{array}$ & & & & \\
\hline B & $\begin{array}{c}\text { Meropenem } \\
+ \text { P. aeruginosa } \\
\text { ATCC } 27853\end{array}$ & 100.0 & 93.5-100.0 & 88.5 & $69.8-97.6$ \\
\hline $\mathrm{C}$ & $\begin{array}{c}\text { Imipenem } \\
+ \text { E. coli } \\
\text { ATCC } 25922\end{array}$ & 100.0 & $93.5-100.0$ & 100.0 & $86.8-100.0$ \\
\hline $\mathrm{D}$ & $\begin{array}{c}\text { Imipenem } \\
+ \text { P. aeruginosa } \\
\text { ATCC } 27853\end{array}$ & 100.0 & $93.5-100.0$ & 15.4 & $4.4-34.9$ \\
\hline
\end{tabular}

\section{Discussion}

A spread of Gram-negative rod strains, resistant to antimicrobials, especially those producing carbapenemases, is a global threat to the effectiveness of antibiotic therapy [16-19]. This phenomenon can be a particular problem for health care units, in which carbapenems are commonly used for the treatment. The prevalence of such strains underlines the need to establish and apply rapid and reliable methods for carbapenemases detection.

Various methods are recommended, and widely used, to detect carbapenem resistance $[4,6]$. One of these is the CIM test, as of typical functional and enzyme synthesisdepending methods, evaluated in this paper. It distinguishes types of bacterial resistance to carbapenems resulting from carbapenemases synthesis from the resistance caused by other mechanisms, e.g., efflux pump - an active antibiotic elimination from bacterial cells [12]. Presence of the latter mentioned mechanism of resistance is of high relevance, particularly in the carbapenem-resistant phenotype in non-fermenting Gram-negative rods (especially $P$. aeruginosa strains). Its presence, additionally, explains the existence of uncommon susceptibility phenotypes, e.g., resistant to carbapenems with remaining sensitivity to chosen cephalosporins [20-22].

In this present work, the diagnostic value of the primary version of the CIM test and its three modified variants was evaluated.

Many studies [12,23-26] have demonstrated the high sensitivity and diagnostic specificity of the CIM test in the detection of carbapenemases produced by Enterobacterales rods. However, few studies have evaluated this test for non-fermenting rods. In one study, conducted by Madkour et al. [27], simultaneously for Enterobacterales and nonfermenting rods strains, CIM diagnostic sensitivity of $95.7 \%$ and a specificity of $95.5 \%$ were observed. The differences observed in the diagnostic sensitivity and specificity of the cited authors may result from different species characteristics, particular strain properties, and the number of the strains included in the study itself.

There are only a few reports in the available literature in which diagnostic parameters of the CIM test for non-fermenting rods were evaluated. In this paper, in variant A of CIM (meropenem + E. coli), false negative results were obtained for three A. baumannii and two P. aeruginosa strains. In addition, for two A. baumannii isolates, the result of $\mathrm{CIM}$ was classified as ambiguous. The false-negative results obtained with CIM may be due to the low level of carbapenemase-encoding gene expressions. In our own research, reduced sensitivity of results for non-fermenting rods was obtained, reaching $87.3 \%$, while maintaining $100 \%$ specificity.

Van der Zwaluw et al. [12], in their study, also obtained two false negative results for non-fermenting rods, resulting in a diagnostic sensitivity of $98.8 \%$. The results of research conducted by Aktaş et al. [28] confirm the results obtained in our study; diagnostic sensitivity of CIM was lowered for A. baumannii and P. aeruginosa strains and reached $90.0 \%$. 
However, the values presented by the last mentioned author have been calculated for all of the tested strains, non-fermenting rods and Enterobacterales altogether.

Another aspect of the study was to assess the impact of modification of CIM on its sensitivity and diagnostic specificity. A replacement of the meropenem disc with an imipenem disc while maintaining E. coli ATCC 25922 reference strain usage (variant C) increased the ability to detect carbapenemase activity among non-fermenting rods. The diagnostic sensitivity and specificity of this method modification reached $100 \%$.

The results of Yamada's [29] research suggested previously that the use of imipenem discs to perform CIM test may result in false positive results for some certain bacteria species. However, these results were obtained for Enterobacterales, and not for nonfermenting rods.

Of note, the use of a meropenem discs may result in a false-negative result in the CIM test for non-fermenting rods. This is especially important for A. baumannii strains that produce oxacillinases most frequently. These enzymes show low hydrolytic activity towards carbapenems.

The effectiveness of imipenem disc application was confirmed by Wan et al. [30] in the simplified Carbapenem Inactivation Method test (sCIM). The use of this carbapenem resulted in the detection of carbapenemase activity in all of the tested A. baumannii and $P$. aeruginosa strains, while using a meropenem disc showed negative results. Our study also showed an increased sensitivity of the test with the imipenem disc compared to the meropenem disc.

An increase in the diagnostic sensitivity and specificity of the CIM test, resulting from the use of the imipenem disc, has also been demonstrated previously by Gutiérrez et al. [31]. The sensitivity and specificity of the test for 266 P. aeruginosa strains was higher in this study using the imipenem disc $(99.4 \%$ and $98.9 \%$, respectively) compared to the meropenem disc ( $91.9 \%$ and $94.7 \%$, respectively). The diagnostic sensitivity obtained in our research $(100 \%)$ may result from a significantly lower number of $P$. aeruginosa strains included in CIM test evaluation.

The results of our study also showed an increased sensitivity of the test with the imipenem disc application compared to the meropenem disc for $A$. baumannii strains with class D carbapenemases (OXA-like enzymes). As it has been previously demonstrated, OXA-like enzymes (e.g., OXA-23) present a much higher turnover rate for imipenem than for other carbapenems, including the applied meropenem [32]. It could explain our observation on OXA-like enzyme-positive A. baumannii isolates.

This study also examined the effect of P. aeruginosa ATCC 27853 reference strain application on the CIM test (variant B and D) ability to detect carbapenemase activity. Of note, this is an innovative approach and the available literature lacks any data on such modification of the CIM test. The value of the diagnostic sensitivity of the CIM test for nonfermenting rods increases, up to $100 \%$, when using the mentioned P. aeruginosa reference strain, compared to its variant using E. coli ATCC 25922 counterpart (87.3\%). Surprisingly, the simultaneous use of the $P$. aeruginosa strain and the imipenem disc significantly reduces the diagnostic specificity of the test, while maintaining its $100 \%$ sensitivity.

In summary, the CIM test is a reliable diagnostic method for detecting carbapenemasepositive strains. In addition, the uncomplicated methodology, relatively low cost and simplicity of interpretation allow for the usage of this method in laboratories too, without specialized equipment. Thus, a number of CIM test variants have been established and applied recently in laboratory practice. Some of them present increased sensitivity of results for particular species of selective carbapenemases, including differentiation between metallo-enzymes and other carbapenemases. Some of them were introduced to shorten, simplify or automate the investigation [33]. The results of our research indicate that the modified versions of CIM significantly improved sensitivity of CIM for non-fermenting Gram-negative bacteria.

Of note, the CIM test requires continuous culture of the chosen reference strain, and the time to obtain the results is relatively long, compared to the Carba NP/CarbAcineto test. 
However, compared to these tests, sensitivity of results, especially for non-fermenting rods, is higher and also shows a high agreement with molecular biology-based methods $[8,9,27]$. This particularly refers to A. baumannii isolates producing OXA-type carbapenemases (Table S2). Positive results of the CIM test, in comparison to generally faster genetic methods, do not provide information on the class or family of carbapenemase detected. However, this is of secondary importance to the treatment reasons. Detection of carbapenemase activity with high sensitivity and specificity is definitely more important, and the CIM test, in primary or modified variants, for particular strain groups, is definitely characterized by such parameters.

\section{Conclusions}

A CIM test is a useful tool to detect carbapenemase activity in Acinetobacter spp. and Pseudomonas spp. representatives.

Introduction of imipenem discs to the standard CIM version enhances diagnostic sensitivity and specificity of the test for non-fermenting rods.

Replacement of E. coli ATCC 25922 with P. aeruginosa ATCC 27853 reference strain in the CIM test results in sensitivity improvement of the test and a decrease in diagnostic specificity for non-fermenting Gram-negative rods.

Application of particular modifications of the CIM test as a standard microbiological procedure in a medical diagnostic laboratory may result in a significant increase of the reliability of carbapenemase detection results.

Supplementary Materials: The following are available online at https:/ / www.mdpi.com/article/10 .3390 /antibiotics10070875/s1. Table S1: the origin of clinical and reference strains used in the study; Table S2: methods used to detect the activity of carbapenemases and/or carbapenemase encoding genes in the tested and reference strains.

Author Contributions: Conceptualization, T.B.; methodology, T.B.; software, T.B. and M.R.; validation, T.B. and M.R.; formal analysis, T.B. and M.R.; investigation, T.B. and M.R.; resources, T.B.; data curation, T.B. and M.R.; writing-original draft preparation, T.B. and M.R.; writing-review and editing, T.B., M.R. and E.G.-K.; visualization, T.B. and M.R.; supervision, T.B.; project administration, T.B. and M.R.; funding acquisition, T.B and M.R. All authors have read and agreed to the published version of the manuscript.

Funding: This research was financially supported by the Collegium Medicum in Bydgoszcz, Nicolaus Copernicus University in Torun, with funds for the maintenance of the research potential of the Microbiology Department (WF PDB 839), and with the support of Students' Scientific Society.

Data Availability Statement: The data presented in this study are available on request from the corresponding author.

Conflicts of Interest: The authors declare no conflict of interest.

\section{References}

1. Behzadi, P.; Baráth, Z.; Gajdács, M. It's Not Easy Being Green: A Narrative Review on the Microbiology, Virulence and Therapeutic Prospects of Multidrug-Resistant Pseudomonas aeruginosa. Antibiotics 2021, 10, 42. [CrossRef] [PubMed]

2. Bonomo, R.A.; Szabo, D. Mechanisms of Multidrug Resistance in Acinetobacter Species and Pseudomonas aeruginosa. Clin. Infect. Dis. 2006, 43, S49-S56. [CrossRef]

3. Breilh, D.; Texier-Maugein, J.; Allaouchiche, B.; Saux, M.-C.; Boselli, E. Carbapenems. J. Chemother. 2013, 25, 1-17. [CrossRef] [PubMed]

4. Codjoe, F.; Donkor, E. Carbapenem Resistance: A Review. Med. Sci. 2017, 6, 1. [CrossRef] [PubMed]

5. Papp-Wallace, K.M.; Endimiani, A.; Taracila, M.A.; Bonomo, R.A. Carbapenems: Past, Present, and Future. Antimicrob. Agents Chemother. 2011, 55, 4943-4960. [CrossRef]

6. The European Committee on Antimicrobial Susceptibility Testing. EUCAST Guidelines for Detection of Resistance Mechanisms and Specific Resistances of Clinical and/or Epidemiological Importance. Available online: https://www.eucast.org/resistance_ mechanisms (accessed on 2 June 2021).

7. Papadimitriou-Olivgeris, M.; Bartzavali, C.; Christofidou, M.; Bereksi, N.; Hey, J.; Zambardi, G.; Spiliopoulou, I. Performance of chromID ${ }^{\circledR}$ CARBA medium for carbapenemases-producing Enterobacteriaceae detection during rectal screening. Eur. J. Clin. Microbiol. Infect. Dis. 2014, 33, 35-40. [CrossRef] [PubMed] 
8. Dortet, L.; Poirel, L.; Errera, C.; Nordmann, P. CarbAcineto NP Test for Rapid Detection of Carbapenemase-Producing Acinetobacter spp. J. Clin. Microbiol. 2014, 52, 2359-2364. [CrossRef] [PubMed]

9. Literacka, E.; Herda, M.; Baraniak, A.; Żabicka, D.; Hryniewicz, W.; Skoczyńska, A.; Gniadkowski, M. Evaluation of the Carba NP test for carbapenemase detection in Enterobacteriaceae, Pseudomonas spp. and Acinetobacter spp., and its practical use in the routine work of a national reference laboratory for susceptibility testing. Eur. J. Clin. Microbiol. Infect. Dis. 2017, 36, 2281-2287. [CrossRef]

10. Nordmann, P.; Poirel, L.; Dortet, L. Rapid Detection of Carbapenemase-producing Enterobacteriaceae. Emerg. Infect. Dis. 2012, 18, 1503-1507. [CrossRef] [PubMed]

11. Rudresh, S.M.; Ravi, G.S.; Sunitha, L.; Hajira, S.N.; Kalaiarasan, E.; Harish, B.N. Simple, rapid, and cost-effective modified Carba NP test for carbapenemase detection among Gram-negative bacteria. J. Lab. Physicians 2017, 9, 303-307. [CrossRef]

12. van der Zwaluw, K.; de Haan, A.; Pluister, G.N.; Bootsma, H.J.; de Neeling, A.J.; Schouls, L.M. The Carbapenem Inactivation Method (CIM), a Simple and Low-Cost Alternative for the Carba NP Test to Assess Phenotypic Carbapenemase Activity in Gram-Negative Rods. PLoS ONE 2015, 10, e0123690. [CrossRef] [PubMed]

13. The European Committee on Antimicrobial Susceptibility Testing. Breakpoint Tables for Interpretation of MICs and Zone Diameters. Version 7.1; 2017. Available online: https:/ / www.eucast.org/clinical_breakpoints (accessed on 12 March 2021).

14. Pierce, V.M.; Simner, P.J.; Lonsway, D.R.; Roe-Carpenter, D.E.; Johnson, J.K.; Brasso, W.B.; Bobenchik, A.M.; Lockett, Z.C.; Charnot-Katsikas, A.; Ferraro, M.J.; et al. Modified Carbapenem Inactivation Method for Phenotypic Detection of Carbapenemase Production among Enterobacteriaceae. J. Clin. Microbiol. 2017, 55, 2321-2333. [CrossRef] [PubMed]

15. EM100 Connect-CLSI M100 ED31. 2021. Available online: http://em100.edaptivedocs.net $/$ GetDoc.aspx?doc=CLSI\%20M100\%2 0ED31:2021\&scope $=$ user (accessed on 6 July 2021).

16. Gheorghe, I.; Novais, A.; Grosso, F.; Rodrigues, C.; Chifiriuc, M.C.; Lazar, V.; Peixe, L. Snapshot on carbapenemase-producing Pseudomonas aeruginosa and Acinetobacter baumannii in Bucharest hospitals reveals unusual clones and novel genetic surroundings for blaOXA-23. J. Antimicrob. Chemother. 2015, 70, 1016-1020. [CrossRef] [PubMed]

17. Hrabák, J.; Chudáčkova, E.; Papagiannitsis, C.C. Detection of carbapenemases in Enterobacteriaceae: A challenge for diagnostic microbiological laboratories. Clin. Microbiol. Infect. 2014, 20, 839-853. [CrossRef]

18. Lautenbach, E.; Synnestvedt, M.; Weiner, M.G.; Bilker, W.B.; Vo, L.; Schein, J.; Kim, M. Imipenem Resistance in Pseudomonas aeruginosa Emergence, Epidemiology, and Impact on Clinical and Economic Outcomes. Infect. Control. Hosp. Epidemiol. 2010, 31, 47-53. [CrossRef] [PubMed]

19. Nordmann, P.; Naas, T.; Poirel, L. Global Spread of Carbapenemase-producing Enterobacteriaceae. Emerg. Infect. Dis. 2011, 17, 1791-1798. [CrossRef]

20. Gajdács, M. Carbapenem-Resistant but Cephalosporin-Susceptible Pseudomonas aeruginosa in Urinary Tract Infections: Opportunity for Colistin Sparing. Antibiotics 2020, 9, 153. [CrossRef]

21. Rampioni, G.; Pillai, C.R.; Longo, F.; Bondi, R.; Baldelli, V.; Messina, M.; Imperi, F.; Visca, P.; Leoni, L. Effect of efflux pump inhibition on Pseudomonas aeruginosa transcriptome and virulence. Sci. Rep. 2017, 7, 11392. [CrossRef]

22. Issa, K.H.B.; Phan, G.; Broutin, I. Functional Mechanism of the Efflux Pumps Transcription Regulators from Pseudomonas aeruginosa Based on 3D Structures. Front. Mol. Biosci. 2018, 5, 57. [CrossRef]

23. Bayraktar, B.; Barış, A.; Malkoçoğlu, G.; Erdemir, D.; Kına, N. Comparison of Carba NP-Direct, Carbapenem Inactivation Method, and $\beta$-CARBA Tests for Detection of Carbapenemase Production in Enterobacteriaceae. Microb. Drug Resist. 2019, $25,97-102$. [CrossRef]

24. Gauthier, L.; Bonnin, R.A.; Dortet, L.; Naas, T. Retrospective and prospective evaluation of the Carbapenem inactivation method for the detection of carbapenemase-producing Enterobacteriaceae. PLoS ONE 2017, 12, e0170769. [CrossRef] [PubMed]

25. Saito, K.; Nakano, R.; Suzuki, Y.; Nakano, A.; Ogawa, Y.; Yonekawa, S.; Endo, S.; Mizuno, F.; Kasahara, K.; Mikasa, K.; et al. Suitability of Carbapenem Inactivation Method (CIM) for Detection of IMP Metallo- $\beta$-Lactamase-Producing Enterobacteriaceae. J. Clin. Microbiol. 2017, 55, 1220-1222. [CrossRef] [PubMed]

26. Yıldız, S.S.; Kaşkatepe, B.; Avcıküçük, H.; Öztürk, Ş. Performance of CarbaNP and CIM tests in OXA-48 carbapenemase-producing Enterobacteriaceae. Acta Microbiol. Immunol. Hung. 2017, 64, 9-16. [CrossRef]

27. Madkour, L.A.; Soliman, M.S.; Hassan, D.M.; Soliman, N.S.; ElMahdy, Y.A. Detection of carbapenemase-producers: Evaluating the performance of the carbapenem inactivation method and Carba NP test versus multiplex PCR. J. Glob. Antimicrob. Resist. 2017, 9, 10-14. [CrossRef]

28. Aktaş, E.; Malkoçoğlu, G.; Otlu, B.; Çopur Çiçek, A.; Külah, C.; Cömert, F.; Sandallı, C.; Gürsoy, N.C.; Erdemir, D.; Bulut, M.E. Evaluation of the Carbapenem Inactivation Method for Detection of Carbapenemase-Producing Gram-Negative Bacteria in Comparison with the RAPIDEC CARBA NP. Microb. Drug Resist. 2017, 23, 457-461. [CrossRef] [PubMed]

29. Yamada, K.; Kashiwa, M.; Arai, K.; Nagano, N.; Saito, R. Comparison of the Modified-Hodge test, Carba NP test, and carbapenem inactivation method as screening methods for carbapenemase-producing Enterobacteriaceae. J. Microbiol. Methods 2016, 128, 48-51. [CrossRef] [PubMed]

30. Wan, D.; Jing, X.; Zhou, H.; Min, X.; Zhang, X.; Wu, T.; Liu, R.; Zeng, J. Differences between meropenem and imipenem disk to detect carbapenemase in gram-negative bacilli using simplified carbapenem inactivation method. J. Infect. Chemother. 2020, 26, 636-639. [CrossRef] [PubMed] 
31. Gutiérrez, S.; Correa, A.; Hernández-Gómez, C.; De La Cadena, E.; Pallares, C.; Villegas, M.V. Detection of carbapenemaseproducing Pseudomonas aeruginosa: Evaluation of the carbapenem inactivation method (CIM). Enferm. Infecc. Microbiol. Clin. 2019, 37, 648-651. [CrossRef]

32. Evans, B.A.; Amyes, S.G.B. OXA $\beta$-lactamases. Clin. Microbiol. Rev. 2014, 27, 241-263. [CrossRef]

33. Humphries, R.M. CIM City: The Game Continues for a Better Carbapenemase Test. J. Clin. Microbiol. 2019, 57, e00353-19. [CrossRef] 